\title{
Acknowledgment of Reviewer performance in 2008
}

\author{
Jos A. E. Spaan
}

Received: 25 June 2009/Accepted: 25 June 2009/Published online: 29 July 2009

(C) The Author(s) 2009. This article is published with open access at Springerlink.com

It is going well with Medical \& Biological Engineering \& Computing (MBEC)! As explained in a series of editorials over the past few years, structural changes were implemented in the journal at practically all levels [2-5]. The most important changes were teaming with a new publisher, Springer, and establishing a new editorial team. The aim, clearly underwritten by the Administrative Council of the International Federation of Medical and Biological Engineering (IFMBE), was to increase the impact of MBEC as measured by the indices published on the Web of Science [1] (http://science.thomsonreuters.com), (i.e., the Impact Factor, IF). We have always seen this as a joint effort of all involved. We also knew that this was a slow process, especially because the indices used to compute the IF cover the journal's production and influence over a series of years. For understanding and support to this process, I am grateful to the efforts of IFMBE's Federation Journal Committee over these last years.

Recently the indices have been updated and indeed success is now measureable and reported publically. Our IF for 2008 increased by $40 \%$ to 1.38 , but more importantly, we anticipate a further significant increase next year based on the citations to MBEC papers published in 2007 and 2008.

Another indication of the MBEC's increased visibility is the observation that the number of citations to all papers published in MBEC over the 47 years of its existence, increased in 2008 by 30\%. This increased citation rate is to MBEC papers accepted under

J. A. E. Spaan ( $\square)$

Amsterdam, The Netherlands

e-mail: MBEC@amc.uva.nl responsibilities of the former editors. Our Journal ranks second in the list of Biomedical Engineering journals when sorted by cited half-life manuscripts, which is 9.8 years. This implies that we have many hallmark publications that are cited even after 10 years.

Essential for the journal is the willingness of our reviewers to evaluate the manuscripts that are submitted to the journal in a timely fashion. We thought it was a good moment to recognize their contributions by publishing their names and indicate the number of reports they wrote in 2008.

We are grateful to the international community of reviewers and authors for contributing to the continuation of our success in serving the Medical and Biological Engineering Community.

Jos AE Spaan.

Editor in Chief

Deputy Editor: Ruben Coronel, Academic Medical Center, Amsterdam, The Netherlands

Associates Editors:

Jenny Dankelman, University of Technology, Delft, The Netherlands

Dario Farina, Aalborg University, Aalborg, Denmark

Andrew McCulloch, University of California, San Diego, USA

Nico A. M. Schellart, Academic Medical Center, Amsterdam, The Netherlands

Maria Siebes, Academic Medical Center, Amsterdam, The Netherlands

Andreas Wahle, University of Iowa, Iowa, USA

Open Access This article is distributed under the terms of the Creative Commons Attribution Noncommercial License which permits any noncommercial use, distribution, and reproduction in any medium, provided the original author(s) and source are credited. 


\section{References}

1. Garfield E (2006) The history and meaning of the journal impact factor. JAMA 295(1):90-93

2. Nagel JH (2006) A new chapter for MBEC. Med Biol Eng Comput $44: 3-4$
3. Spaan JA (2006) Welcome back to MBEC: a new look and a fresh start. Med Biol Eng Comput 44:1-2

4. Spaan JA (2007) A happy new year. Med Biol Eng Comput 45:1

5. Spaan JA (2009) Changes in editorial team and policies of MBEC in 2009. Med Biol Eng Comput 47:1-2 